BERSTED, C. T., BROWN, B. R., \& EVANS, S. H. A standard set of VARGUS 7 patterns at three levels of schematic redundancy. Psy chonomic Monograph Supplements, 1968, 2 (13, Whole No. 29), 251-282.

BROWN, B. R., WALKER, D.W., \& EVANS, S. H. Schematic concept formation as a function of constraint redundancy and knowledge of results. Psychonomic Science, 1968, 11, 75-76.

EDMONDS, E. M., MUELLER, M. R., \& EVANS, S. H. Effects of knowledge of results on mixed schema discrimination. Psychonomic Science, $1966,6,377-378$

EVANS, S. H. A model for perceptual category formation. Unpublished doctoral dissertation, Texas Christian University, 1964.

EVANS, S. H. A brief statement of schema theory. Psychonomic Science, 1967a, 8, 87-88.

EVANS, S. H. VARGUS 7: Computed patterns from Markov processes. Behavioral Science, 1967b, 12, 323-328.

EVANS, S. H. Redundancy as a variable in pattern perception. Psychological Bulletin, 1967c, 104-113.

EVANS, S. H., \& ARNOULT, M. D. Schematic concept formation: Demonstration in a free sorting task. Psychonomic Science, 1967, 9, 221-222.
EVANS, S. H., \& EDMONDS, E. M. Schema discrimination as a function of training Psychonomic Science, 1966, 5, 303-304.

GIBSON, J. J. Perception as a function of stimulation. In S. Koch (Ed.), Psychology: $A$ study of a science. Vol. 1. New York: McGraw-Hill, 1959.

GIBSON, J. J., \& GIBSON, E. J. Perceptual leaming: Differentiation or enrichment? Psychological Review, 1955, 62, 32-41.

HARVARD COMPUTATION LABORATORY. A table of the cumulative binomial Harvard University Press, 1955.

OLDFIELD, R. C. Memory mechanisms and the theory of schemata. British Journal of Psychology, 1954, 45, 14-23.

ROSSER, E. M.Categorization and discrimination of tone sequences. Unpublished doctoral dissertation, Harvard, 1967.

WOODWORTH, R. S. Experimental Psychology. New York: Holt, 1938. NOTE

1. This research is a part of the first author's doctoral dissertation submitted at Texas Christian University in 1968. Support for the research was provided by a Department of Defense Project THEMIS (DAADO5-68-C-0176) under the Department of the Army.

\title{
Sequential blanking and visual form perception'
}

A. BELL, R. G. FORSTER, ${ }^{2}$ F. J. FINNEGAN, ${ }^{3}$ M. KATZ, J. I. La SUSA,4 and M.S. MAYZNER, New York University, Bronx, N.Y. 10453

The present study replicates and extends previous findings by Julesz, in which he studied sequential and nonsequential presentation orders for the sides of variously shaped polygons. Our results fully confïm his findings and further suggest that his results are but still another instance of sequential blanking effects in man's visual information processing system.

In a recent paper, Julesz (1967) studied visual form perception for various polygons by presenting the sides of the polygons, which were thin bright slits on a black background, cyclically in sequential and nonsequential orders, at various display rates. The Ss were requested to indicate when the polygon in question was perceived as a single Gestalt, i.e., all sides joining and appearing to occur simultaneously to $S$. The results clearly showed that for $S$ to report perceiving the polygon in question as a single Gestalt, the display time per side needed to be about 5 to $10 \mathrm{msec}$ lower for the nonsequential presentation order than for the sequential presentation order. Julesz (1967) conceptualizes his findings in the following terms: "One recognition mechanism might be based on scanning sequential ly each side of the polygon and noting the temporal order of vertices where the jump from one set of orientation detectors to another occurs. A conceptually simpler but actually more complex model might be based on parallel organization. Here each possible slit detector combination forms a complex unit which might simultaneously process each side of the polygon in question [pp. 139-140]." Julesz (1967) concludes: "Since in the experiments for both the sequential and nonsequential presentation the same perceptual criterion of seeing a Gestalt was used, we might expect the polygon detector would be insensitive to the temporal order of the occurrence of edges. This expectation is in disagreement with the findings [p. 141]." Thus, it would appear from Julesz's results that the parallel organization hypothesis does not yield the expected results and that sequential organization processes predominate.

Since Julesz's finding has considerable theoretical importance for visual form perception, it was decided to replicate his study, using a computer-based cathode-ray tube (CRT) display system, with a larger variety of polygons and to employ a slightly different psychophysical procedure, as well as the one employed by Julesz. In addition, Julesz incidentally noted ${ }^{5}$ that in the nonsequential order, $\mathrm{Ss}$ reported seeing sides missing from the polygon prior to perceiving it as a single Gestalt, and we were particularly interested in seeing whether this finding could be replicated and whether it might not be another instance of our apparently new perceptual phenomenon of "sequential blanking" (Mayzner, Tresselt, \& Cohen, 1966; Mayzner, Tresselt, \& Helfer, $1967 \mathrm{a}, \mathrm{b})$.

\section{SUBJECTS}

Five male Ss were employed for the main study and an additional 14 Ss were exposed to certain critical display configurations in a subsequent group demonstration of the effects which were found in the main study. APPARATUS

The eight pairs of polygons that were studied were presented on two Fairchild CRT display consoles simultaneou sly, allowing two Ss to be tested simultaneously. Both Fairchild CRT display consoles were slaved to a 340 Master Display, driven by a PDP.7 digital computer. A complete description of this system may be found in our previous papers (Mayzner, 1968; Mayzner, Tresselt, \& Helfer, 1967a)

\section{MATERIALS}

The stimulus materials consisted of the five polygons employed by Julesz (1967), i.e., a pentagon, a hexagon, and a triangle, but with each side divided in half, so that six sides were displayed, either sequentially or nonsequentially, and a second pentagon and triangle, in which the vertices or vertices and part sides were displayed, either sequentially or nonsequentially, and labelled as in Julesz's paper, A, B, C, D, and E, respectively. In addition, three new polygons were added, labelled $F, G$, and $H$, respectively, and consisted of a very irregular 12-sided polygon, a square, and a very irregular sixsided polygon. Each of the eight polygon types, A through $\mathrm{H}$, was presented on the CRT in pairs, side by side, with the sides of one of the pairs of polygons presented sequentially, while 1 in. to the right an identically shaped polygon was displayed, but with its sides presented in a nonsequential order, following Julesz's orders of side presentation exactly, for his polygons, A through $E$, and employing a random nonsequential order of side presentation for Polygons $F, G$, and $H$. Each polygon was approxi- 
Table 1

Display Time per Side (in msec) to Perceive Polygon as a Single Gestalt

\begin{tabular}{lcccc}
\hline & \multicolumn{2}{c}{ Nonsequential Order } & \multicolumn{2}{c}{ Sequential Order } \\
Polygon Type & Julesz's Results & Present Study & Julesz's Results & Present Study \\
\hline A (5 sides) & 12 & $25-30 *$ & 20 & $35-40$ \\
B (6 sides) & 6 & $20-25$ & 9 & $30-35$ \\
C (6 sides) & 6 & 20 & 8 & 30 \\
D (5 sides) & 11 & $25-30$ & 18 & $35-40$ \\
E (6 sides) & 7 & 10 & 11 & 30 \\
F (12 sides) & - & 45 & - & 20 \\
G (4 sides) & - & 30 & - & 50 \\
H (6 sides) & - & - & - & 35 \\
\hline
\end{tabular}

* Where two values are given, one, two, or three of the five Ss gave one value while the remaining Ss gave the other value.

mately 1 in. in width at its widest dimension and $S$ was seated 70 in. from the CRT. Each side was approximately $1 \mathrm{~mL}$ in luminance as measured with a Macbeth illuminometer. Julesz reports no effects on his findings as a result of visual angle of the diameter of the polygon, width of sides or slits, or contrast, and our results confirm his observations.

\section{PROCEDURE}

The five Ss were presented with the eight polygon pairs, $A$ through $H$, one pair at a time, with one polygon of each pair with a sequential order of side presentation and the other polygon of each pair with a nonsi quential order of side presentation, in contrast to Julesz's procedure, in which only a single polygon was presented at one time. Each pair was shown first at $50 \mathrm{msec}$ per side and the times decreased in 5 -msec increments to 5 msec per side and then incre ased in $5-\mathrm{msec}$ increments back to $50 \mathrm{msec}$ per side. Time between sides was $50 \mu \mathrm{sec}$ and the display was cycled continuously until $S$ made a response for each of the different display times per side that were examined. This procedure was repeated 10 times for each $S$ and on each descending and ascending trial $S$ was instructed to report when each of the two polygons of a particular pair he was observing became a single Gestalt (i.e., all sides joining and occurring simultaneously). On another set of control trials (following Julesz's procedure), the five $S$ s observed only one or the other of the two polygons of each pair by masking over one of the two polygons being displayed. The times at which each $S$ reported a given polygon as being perceived as a single Gestalt were recorded and never varied more than $5 \mathrm{msec}$ for any given individual or between individuals, on any of the trials, for both single and paired presentations.

\section{RESULTS AND DISCUSSION}

The major findings of the study are presented in Table 1, which shows the display times per side (in $\mathrm{msec}$ ) required for the $\mathrm{Ss}$ of this study to yield a report of a single Gestalt under conditions of nonsequential and sequential presentation order for eight different polygons. Julesz's (1967) data for the five polygons he examined is also given in Table 1 and his data show the same differences between nonsequential and sequential orders as our results, except his differences are somewhat smaller.
As Table 1 indicates our data was exceptionally stable for the five Ss tested, and the values shown were, with three minor exceptions, in agreement with those values obtained on the control trials, in which $\mathrm{S}$ observed only a single polygon at a time, following Julesz's procedure. Further, using just the values shown in Table 1, with the two-polygon comparison procedure, an additional group of $14 \mathrm{Ss}$ were shown the critical display times of Table 1 , in a class demonstration, and every $S$ with but two exceptions agreed with the findings shown in Table 1.

It should also be noted that with the two-polygon comparison procedure, $S$ views both polygons simultaneously, and under this viewing mode, the blanking effect of certain sides incidentally observed by Julesz 5 is strikingly confirmed in this study. For example, with each of the eight polygon pairs examined, when that display time per side is reached that produces a report of a single Gestalt under the sequential order condition, it is perfectly clear and was reported by all $19 \mathrm{Ss}$ examined, that the second polygon being displayed had up to about one-half of its sides missing, which explains why the nonsequential order poly. gon is not reported as a single Gestalt at the same display time per side as the sequential order polygon, thus providing an explanation for Julesz's findings, in terms of our sequential blanking effect, rather than the sequential vs parallel processing hypothesis, as advanced by Julesz. Further query of the Ss revealed that in every polygon with sides missing, under the nonsequential order condition, at the appropriate display time per side, if Ss were requested to point at the missing sides, they were always, without any exceptions whatsoever, the first half of the polygon sides being displayed.

It would appear that these phenomenally missing sides, even though they are, in fact, being displayed, represent another instance of the sequential blanking effect (Mayzner, Tresselt, \& Cohen, 1966, Mayzner, Tresselt. \& Helfer, 1967a,b), in which up to approximately the first half of an input array may not be perceived at certain critical input display rates and display orders. To further substantiate the possible relationship of the missing sides in the polygons to the sequential blanking effect, the $14 \mathrm{Ss}$ in the class demonstration were shown the eight polygon pairs of this study, at the display times per side shown in Table 1, but now rather than continuously cycling the display, the sides were displayed just once and $S$ was then requested to make his judgment, this single cycle condition being identical with the procedures previously employed when studying the sequential blanking phenomenon (Mayzner, Tresselt, \& Cohen, 1966; Mayzner, Tresselt, \& Helfer, $1967 \mathrm{a}, \mathrm{b})$. To our considerable surprise the first half of the sides in both polygons being displayed were now reported as missing, and thus it would appear that not only do the findings under the continuous cycling case represent another instance of sequential blanking, but this effect can be greatly magnified (i.e., both polygons show the effect) if only a single cycle of the sides is examined, a condition that Julesz did not study.

It remains for further work to assess more fully and completely whether the missing sides of the polygons represent, without question, still another instance of the sequential blanking effect. It is encouraging to note, however, that if one multiplies the number of sides of any given polygon in question by the display time per side for the particular polygon in question, the predominate value obtained is approximately $200 \mathrm{msec}$ of total display time for a single display cycle, which also is the value for a single display cycle which generally maximizes the sequential blanking effect.

\section{REFERENCES}

JULESZ, B. Some recent studies in vision relevant to form perception. In W. Wathen-Dunn (Ed.), Models for the perception of speech and visual form. Cambridge, Mass.: The M.I.T. Press, 1967.

MAYZNER, M. S. The research potential of a computer-based cathode-ray tube display sy stem. Behavior Research Methods \& Instrumentation, 1968, 1,41-43.

MAYZNER, M.S., TRESSELT, M.E.,\& COHEN, A. Preliminary findings on some effects of very fast sequential input rates on perception. Psychonomic Science, 1966, 6, 513-514.

MAYZNER, M. S., TRESSELT, M. E., \& HELFER, M.S. A research strategy for studying certain effects of very fast sequential input rates on perception. Psychonomic Monograph Supplements, 1967a, 2, (5, Whole No. 21), 73-81.

MAYZNER, M. S., TRESSELT, M. E., \& HELFER, M. S. A provisional model of visual information processing with sequential inputs. Psychonomic Monograph Supplements, $1967 \mathrm{~b}$. 2, (7, Whole No. 23), 91-108.

$$
\text { NOTES }
$$

1. This research was supported by Grant No. GB-8037 from the National Science Foundation to the last author.

2, 3, 4. Present address: IBM-SMD, Kingston. N.Y. 12401 .

5. Personal communication. 